\title{
OLIVANTE DE LAURA Y LA REFLEXIÓN SOBRE EL VESTIDO* REFLECTIONS UPON CLOTHING IN OLIVANTE DE LAURA
}

\author{
Tomasa Pilar Pastrana Santamarta \\ IES San Andrés (Léon)
}

\begin{abstract}
RESUMEN
Antonio de Torquemada nos ofrece en su obra Olivante de Laura las alusiones a prendas propias de los libros de caballerías; sin embargo, aporta una novedad frente a otras de su género pues la trama cuestiona la validez del vestido como elemento marcador de jerarquía. La noción medieval de «cada uno según su estado» se convierte así en objeto de debate por parte de los propios personajes. El héroe viste con ropas no acordes con su estatus para poder acercarse a su amada, al igual que hacían las gentes de la época para poder conseguir sus fines. A partir de este hecho, Torquemada muestra sutilmente los cambios que la sociedad está sufriendo y cómo se hace necesario establecer en vez del vestido, otro elemento más eficaz que pueda representar las jerarquías sociales, como pudiera ser el linaje o la sangre. Palabras clave: vestido, libros de caballerías, renacimiento, jerarquía, linaje.
\end{abstract}

\section{ABSTRACT}

Antonio de Torquemada displays in Olivante de Laura the typical references to clothing and textiles used in other chivalric books. However, he innovates as he questions the capacity for dress to convey hierarchy. The medieval notion of dressing «according to one's status» becomes now the central topic for debate about which the main characters discuss. Following the Renaissance trend, the hero disguises himself as a shepherd in order to approach his loved one. His behavior is a reflection of the times, when people also wear clothes not appropriate to their status. It is from here that Torquemada subtly shows the way society is changing and claims for a new and more effective method to determine and measure hierarchy. Clothing will no longer be valid, he then proposes linage.

KEY WORDS: clothes, chivalric books, renaissance, hierarchy, lineage.

\footnotetext{
* Recibido: 17-03-2019 / Aceptado: 23-09-2019.
} 


\section{INTRODUCCIÓN}

Antonio de Torquemada (1507-1569), humanista nacido en Astorga y secretario del Conde de Benavente, sucumbe a la tentación de escribir un libro de caballerías cuando ya el género estaba consagrado. Habían pasado más de 50 años desde que Garci Rodríguez de Montalbo publicara Amadís de Gaula (1508), pero esto no fue óbice para que Torquemada a pesar de haber renegado de los libros de caballerías por su estilo enrevesado e ininteligible en su Manual de escribientes publicara en 1564, Historia del invencible cavallero don Olivante de Laura, príncipe de Macedonia, que por sus admirables hazañas vino a ser emperador de Constantinopla, agora nuevamente sacada a la luz, libro hoy conocido como Olivante de Laura ${ }^{1}$. Señala Muguruza que el autor había mostrado en aquella obra su preocupación de filólogo por el buen uso de la retórica y la lingüística, algo que criticaba de los libros de caballerías pero que él se encargará con máximo prurito de compensar en Olivante de Laura. Quizás sea ese exceso de celo lo que hiciera que Cervantes condenara la obra como arrogante en El Quijote y fuera merecedora de las llamas. Sin embargo, a juzgar por las menciones que existen a esta obra en inventarios de libreros de la época y en registros de barcos destinados a América, gozó de éxito en su momento a pesar de que solo tuvo una edición de la que se conservan numerosos ejemplares ${ }^{2}$.

No faltan en el libro las aventuras propias de este género: caballeros y doncellas enamorados, aventuras maravillosas, jayanes cuyos modales y atuendo son un burdo remedo de las convenciones cortesanas, monstruos híbridos que recuerdan la tradición de los bestiarios, etc. El gusto por la retórica se ve en los largos parlamentos de los personajes, en sus debates y en el gusto por una comicidad basada en el juego con el discurso. Torquemada, por su oficio sometido a las limitaciones y rigidez del lenguaje jurídico, se permite en esta obra hacer uso de su libertad creadora. Atiendo en esta breve comunicación a uno de los aspectos que se debaten en el libro: el atuendo.

\footnotetext{
${ }^{1}$ I. Muguruza Roca, «El pastor en los libros de caballerías: El caso del Olivante de Laura, de Antonio de Torquemada», Cuadernos para la investigación de la literatura hispánica, 20 (1995), pp. 197-215.

${ }^{2}$ En la Biblioteca de Cataluña: Bon 9-IV-9; en la Biblioteca Nacional de Madrid: R-862 (con partes manuscritas), R-2475, R-3364, R-26727; en la Biblioteca Universitaria de Valencia: R-1/133; en la British Library de Londres: 634.1.21, G.10286; un ejemplar incompleto en la Hispanic Society Library de Nueva York; en la Bibliothèque Arsenal de Paris: Rés.Fol.B.L.972; en la Bibliothèque Mazarine de París:373; en la Bibliothèque Nationale de Paris: Rés. Y2 356. Hay una edición moderna del libro a cargo de Isabel Muguruza, quien publicó las obras completas de Antonio de Torquemada en el año 1997 en la Fundación José Antonio Castro. Anteriormente, la misma autora había publicado en microfichas su tesis doctoral Estudio y edición del "Olivante de Laura», de Antonio de Torquemada en 1994. Igualmente, este texto está digitalizado y forma parte del Corpus of Hispanic Chivalric Romances a cargo de Ivy Corfis.
} 


\section{ANTONio de Torquemada y SU OPINIÓN SOBRE El VESTIDO EN LA ÉPOCA}

A pesar de que las menciones al vestido en Olivante de Laura desde un punto de vista cuantitativo son similares a las existentes en otras obras del mismo género, pues se citan los tejidos y prendas convencionales en las situaciones más habituales -sedas y brocados presentes en entradas, recibimientos, justas, andas cubiertas con paños fúnebres, etc.-, la presencia del traje toma una dimensión diferente gracias al debate que en torno a él se establece, algo que obedece a la situación histórica del momento ${ }^{3}$.

El Olivante de Laura no critica el gasto excesivo en que la sociedad incurría por estar pendiente de las modas, algo que sí criticaba el autor en sus Coloquios satíricos (1553) como señala Bernis: «los usos e invenciones nuevos de cada día desasosiegan a las gentes y acaban las haciendas ${ }^{4} \gg$. Otros escritores de la época compartían la misma opinión, así Antonio de Guevara en Aviso de privados (1539) habla de la «nueva locura» que supone cambiar de ropa por antojo obedeciendo los dictámenes de la moda 5 . Antonio de Torquemada se centra en su libro de caballerías en reflexionar sobre el atuendo como elemento de categorización social, tema que también apuntaba en los mencionados Coloquios satíricos: «y de lo que a mí me toma gana de reír es de ver que los oficiales y los hombres comunes andan tan aderezados y puestos en orden que no se diferencian en el hábito de los caballeros y poderosos» ${ }^{6}$.

El concepto de jerarquía y su materialización en el vestido, como recuerda la conocida expresión: «cada uno según su estado», se convierten en objeto de debate en varios capítulos, pues la relación entre el vestido y el individuo llegaba entonces hasta unos límites que hoy no son comparables. Es necesario recordar, como señala Jones, que en el siglo xvi los vestidos no son meros objetos, sino que se consideran una extensión de la persona y por ello se llega a identificar el valor económico de las prendas con el valor moral de quien las luce ${ }^{7}$. Esta aserción, que era una incuestionable creencia y un principio de consolidación social, parece tambalearse en la propia sociedad coetánea al

\footnotetext{
${ }^{3}$ En Olivante de Laura existen 37 menciones a tejidos, algo más que en Palmerín de Olivia, Lepolemo, Reimundo de Grecia o Claribalte, con 22, 23, 16 y 4 respectivamente. Las menciones a prendas son abundantes, 177, destacando el término «hábito».

${ }^{4}$ A. de Torquemada, Coloquios satíricos, Nueva biblioteca de autores españoles, vII, p. 529. Citado en: C. Bernis, Indumentaria española en tiempos de Carlos V, Madrid, Instituto Diego Velázquez del Consejo Superior de Investigaciones Científicas, 1962, p. 31.
}

${ }^{5}$ A. de Guevara, Aviso de privados, vIII, pp. 146-147. Disponible en: http://www.filosofia.org/cla/gue/ guepc.htm [consultado 03-03-2019].

${ }^{6}$ A. de Torquemada, Coloquios satíricos, Nueva Biblioteca de Autores Españoles, vII, p. 526. Citado en C. Bernis, ob. cit., p. 11.

${ }^{7}$ A. R. Jones y P. Stallybrass, Renaissance Clothing and the Materials of Memory, New York, Cambridge University Press, 2003. 
autor, a juzgar por las duras críticas de Torquemada hacia aquellos que contravenían la ortodoxia en el vestir.

\section{Olivante De LAuRA Y El Vestido}

\subsection{LA REFLEXIÓN SOBRE EL VESTIDO COMO MARCADOR DE CLASE EN LA OBRA}

En Olivante de Laura, los diálogos de los personajes giran en torno al tema del atuendo gracias a la introducción de un pastor, personaje idealizado el Renacimiento por su cercanía a la naturaleza y por asociarse con un mundo puro y contemplativo. Esta figura, aunque aparece en el género de los libros de caballerías de la mano de Feliciano de Silva en Amadís de Grecia (1530), ganará preponderancia tras la publicación de Los siete libros de Diana de Jorge de Montemayor (1559), aunque el propio Torquemada en sus Coloquios satíricos (1553) ya había incluido a los pastores como personajes en su séptimo Coloquio pastoril, con el que se cierra esta obra ${ }^{8}$.

Este personaje, propio de la narrativa bucólica, se convierte en uno de los pilares fundamentales de Olivante de Laura pues permite al autor articular en torno a él la verdadera trama del libro, la cuestión del atuendo y su significado. El tema del vestido, presente en todos los libros de caballerías, toma otra dimensión pues se analiza desde un prisma social y se cuestiona su validez como trasmisor de los inamovibles principios jerárquicos de la sociedad contemporánea al autor. Si atendemos a los datos cuantitativos, el vocablo «hábito» con el significado de «vestido» se menciona en 24 ocasiones, y es la prenda que más veces aparece en la obra. Además, contrastando este libro con otros del mismo género, es igualmente la obra que más veces hace uso de esta palabra.

Además, cabe destacar que Torquemada consigue reflexionar sobre el vestido no a través de su voz de narrador, como venía siendo habitual en otras obras de este género en las que los narradores interpolaban reflexiones o comentarios, sino a través de los personajes. Aquí, son ellos quienes verbalizan sus opiniones adoptando distintos puntos de vista con respecto al «hábito» que visten Silvano y Sileno, lo que permite poner en escena la polémica que alrededor del vestido existía en el momento?.

Por otro lado, el autor crea un debate sobre el vestido partiendo de una situación que refleja de forma inversa lo que ocurría en la sociedad. De esta manera, aunque Torquemada en sus obras ensayísticas criticaba las malas costumbres de las gentes

\footnotetext{
${ }^{8}$ I. Muguruza Roca, art. cit., p. 197.

${ }^{9}$ Sileno es el nombre que Olivante toma cuando se disfraza de pastor. 
de forma directa, en su obra de ficción Olivante de Laura la crítica es implícita, pues en lugar de interpelar a quien viste con prendas más lujosas de las que debe, interpela a quien rechaza las ropas lujosas a favor de otras más viles. El mensaje es el mismo: provoca el mismo rechazo o desazón ver a alguien de jerarquía baja con costumbres poco pulidas y groseras usando ropas nobles, como ver a alguien noble vestido de pastor. De hecho, las interlocuciones de varios personajes, pero especialmente las de la princesa Lucenda y la infanta Galarcia, muestran la perplejidad que causa ver a unos pastores -así caracterizados por sus prendas o «hábito»- con la apostura y maneras propias de los cortesanos.

Y assí se llegaron tan cerca de los corredores que enteramente el uno y el otro podían bien juzgar lo que tanto avían desseado, siendo mirados de todos, que espantados estavan de ver la estraña apostura y buena dispusición de los dos pastores, pareciéndoles cosa muy contraria a razón que tanta hermosura en tan grossero ábito estuviesse encerrada. (Olivante de Laura, I, XxIV, p. 229).

De hecho, el propio Olivante, en la primera aparición del pastor Silvano en escena, se sorprende al verle conmovido por amor hacia la infanta Galarcia: «siendo un pastor, en quien por razón devía aver tan pobre juyzio para caber tan mortal y doloroso sentimiento» (Olivante de Laura, I, XXIII, p. 218). No obstante, el héroe se presta a disfrazarse de pastor para ayudarle pues está dispuesto a correr este riesgo porque así también él podrá acercarse a la corte y a su amada, la princesa Lucenda.

- Señor Peliscán, yo he prometido un don a Silvano, el qual me ha pedido una cosa que no poco holgaréis de oýr: que yo vaya oy con él donde la infanta Galarcia está, dexando las armas y vestido de semejantes vestiduras que las suyas. Y como sea cosa de que yo tan poco perjuyzio reciba, y yendo disfraçado en su hábito podré tomar lengua de las cosas de la corte y saber lo que después de venido más nos conviene hazer, no le he querido negar su demanda. (Olivante de Laura, I, XXIV, p. 226).

Aunque Olivante resta importancia a este atrevimiento ante Peliscán, como muestra la cita anterior, en otros momentos se trasluce su preocupación y así intentará que «en aquel hábito de los de la casa no fuesse visto» (Olivante de Laura, I, Xxv, p. 237). De hecho, Peliscán no entiende por qué Olivante adopta ropas humildes pues se da cuenta de la contravención social en que incurre:

Y no puedo dexar de quejarme desto, que no puedo pensar que sin mucha causa en esse hábito os ayáis assí salido, sin que yo supiesse dónde ni por qué lo hagáis. (Olivante de Laura, I, Xxx, p.282).

En la misma línea se pronuncia la infanta Galarcia, que percibe el peligro subsiguiente al adoptar una identidad falsa.

Y si debaxo del grossero hábito pastoril se encierra persona que merezca ser amada, como avéis sospechado, bien empleado es en él el amor si por vuestra causa en tal estado 
ha venido que para solamente veros se aya puesto en tan gran baxeza y peligro como de ser conocido le podía venir. (Olivante de Laura, I, XXV, p. 244).

En esta época, las rígidas normas por las que los estamentos sociales se regulaban estipulan no solo el número de sirvientes, cantidad de rentas, y trabajos aptos para cada uno sino también la forma de vestir. El uso del vestido estaba legislado a través de pragmáticas y se imponían penas económicas a los contraventores requisando los vestidos o poniendo multas por el doble o más del valor de la prenda. Estas leyes suntuarias estaban indicadas para frenar el gasto superfluo y limitar el deseo aparentar de las gentes ${ }^{10}$. Sin embargo, el caso que se presenta en Olivante de Laura, donde un personaje adopta prendas inferiores, no está legislado formalmente, aunque se sabe que existen penas sociales como la humillación y la pérdida de la honra al adoptar prendas de una jerarquía inferior. Vestir con ropas inapropiadas para el estatus implica una degradación voluntaria que estigmatiza, un ataque al orden establecido, algo en lo que no podían incurrir sus valedores, además dar cierto valor superior a unas prendas humildes que nunca debieran ser ensalzadas.

\subsection{El uso del disfraz en Olivante de Laura}

El uso del disfraz era habitual en la época y no solo en la literatura pues sabemos que incluso Felipe iI en alguna ocasión salía disfrazado con el fin de pasar desapercibido a su paso por las ciudades ${ }^{11}$. Aventuras de este tipo se recogen en multitud de libros de caballerías y en otros géneros literarios, sin embargo, la diferencia entre estas escenas y lo que se observa en Olivante de Laura radica en que el recurso al disfraz aquí no es algo puntual para facilitar encuentros amorosos pactados entre dos amantes, para liberar a alguien de la muerte, etc. En la obra de Torquemada el disfraz deja de ser un elemento subsidiario o anecdótico de la trama y se convierte en un aspecto clave de la misma. Es cierto que el disfraz de pastor responde a una tradición literaria existente y que en este momento está en boga, como señalé antes, pero el autor hace un uso ambivalente del mismo pues, además de permitirle presentar el bucolismo, el amor platónico, églogas, etc., le da pie a señalar la necesidad de tener otros marcadores de jerarquía social distintos al atuendo. Así, Torquemada pone a debate la premisa de la época que equipara el vestido con el valor de la persona, a la que clasifica en su faceta social, económica y moral. Presenta lo que a priori sería inconcebible, que personas de espíritu noble vistan con prendas humildes, siempre asociadas con caracteres incultos

\footnotetext{
${ }^{10}$ Véase J. Sempere y Guarinos, Historia del lujo y de las leyes suntuarias de España, vols. I-II, Gráficas Bachende, Madrid, 1788.

${ }^{11}$ En 1585, Felipe II entró en Barcelona sin ser visto y Luis Cabrera de Córdoba explica «entró de noche por excusar ceremonias antiquísimas, mantenidas de los catalanes por sagradas e inalterables (pero) no convenientes a la grandeza de los presentes reyes». M. J. Del Río Barredo, Madrid, Urbs Regia. La capital ceremonial de la Monarquía Católica, Madrid, Marcial Pons, 2000, p. 25.
} 
y primitivos. Esta situación también tenía un paralelo en la sociedad del momento en la que muchos nobles empobrecidos no podrían vestir como les era conveniente.

La princesa, que hasta allí, embebida en mirar a Olivante, rebolviendo muchas cosas en su pensamiento avía estado, y sospechando que el hábito que tan crecida hermosura encubría no fuesse suyo, volviéndose a Silvano, con un sospiro que sin sentirlo con mucho dolor se le salió de las entrañas, le dixo:

- Silvano, ¿dónde hallaste tan buena compañía como has traýdo contigo? ¿Por ventura andávades los dos tras el ganado juntos en la floresta donde tu padre habitava? (Olivante de Laura, I, XXIV, p. 233).

Hasta que la verdadera identidad de los dos pastores no se desvela, la trama consiste en el enfrentamiento causado por las contradicciones entre la aparente realidad y los presupuestos sobre los que la sociedad jerárquica se sustenta.

\subsection{LA SANGRE COMO MARCADOR DE CLASE}

Aunque la Arcadia ideal es de imposible traslación a una sociedad rígidamente jerarquizada, el autor coloca a sus personajes en una posición que les permite recrearla por unos instantes, pues se hace posible dentro de su mundo de ficción que alguien noble vista con prendas viles, que un pastor tenga modales cultivados, y que la vida campestre se prefiera a la cortesana, como ocurre en los capítulos finales cuando los caballeros y el emperador Archelao se encuentran en la casa de la pastora Silveida: «se tornaron a sentar donde el fuego estava en aquella pobre casa, con tan gran contentamiento y alegría que ninguna falta les hazían para ello las riquezas del imperial palacio de Constantinopla». (Olivante de Laura, III, XXIII, p. 867).

Sin embargo, este mundo ideal solo tendría cabida en la ficción, pues la realidad es muy distinta y en ella la diferenciación jerárquica es la norma. Torquemada, a través de los distintos personajes de su obra, cuestiona la validez de tomar como elemento definitorio de jerarquía social algo tan externo e intercambiable como el vestido. Al igual que ocurría en la realidad contemporánea al autor, la observancia de estas leyes del vestido se está resquebrajando y ya nadie obedece las normas establecidas desde antiguo. En efecto, la obra de Torquemada muestra que un vil hábito de pastor no sirve para ocultar la nobleza de quien lo lleva, y del mismo modo tampoco lo contrario es posible. En la obra literaria, ni Olivante, ni Silvano son pastores; el primero se había disfrazado delante del lector, el segundo lleva un disfraz sin saberlo pues en realidad es hijo del emperador y la pastora Silveida, como se desvela en los últimos capítulos de la obra. Este uso aleatorio del vestido no significa que esté Torquemada en contra de la compartimentación social y las jerarquías, sino en contra de que el vestido sea el elemento diferenciador, como sutilmente se muestra en la trama de la obra. 
El final que propone el autor responde a la ortodoxia de la época pues la obra concluye con la restauración del orden existente y con el mantenimiento de las convenciones sociales. Sin embargo, hay que recordar que, hasta llegar a la anagnórisis, el lector ha leído cientos de páginas -no en vano Cervantes llama a la obra «tonel»- en las que probablemente ha tenido tiempo para reflexionar sobre el concepto del atuendo y su significado en la obra literaria y en la realidad.

Torquemada no condena la pobreza de la madre de Silvano por ser pastora, que no resta calidad al hijo: «aunque os aya faltado el valor que las riquezas y linage os pudieran poner, no os olvidó la fortuna en dotaros de muy gran virtud y bondad» (Olivante de Laura, III, XXIII, p. 872), pues es de casa real. Revelado su origen nobilísimo, el pastor Silvano no se ocupará de procurarse vestidos lujosos con los que manifestar visualmente su estatus. Su identidad no necesitará de prendas que la reafirmen, pues su nobleza y valor habían quedado claros ya desde el comienzo de la obra y ahora se ratifican aludiendo a un aspecto de mayor preeminencia, su sangre regia. El linaje del que procede será el salvoconducto que le permita conseguir el amor de Galarcia, y ella igualmente es consciente de que su ascendencia noble tiene más valor que cualquier riqueza material, y expresa aliviada que ahora podrá «dexar de ser culpada del verdadero amor que le tenía» (Olivante de Laura, III, XXIV, p. 878).

Mas sobre todos era la alegría de Silvano estremada, no tanto por lo que en ser hijo de un tan soberano príncipe ganava como por parecerle que no le faltava del todo el merecimiento para osar servir a su señora Galarcia (Olivante de Laura, III, XXIII, p. 873).

\section{Conclusión}

Antonio de Torquemada, acaso hastiado por el devenir de los tiempos que parece avasallar las convenciones del vestido, adopta en este libro de caballerías una perspectiva que imita de forma inversa lo que se ve en la realidad. El protagonista de Olivante de Laura no guardará decoro en el vestir con intención de conseguir su objetivo amoroso, y así, igual que en la vida cotidiana los hombres comunes se disfrazan de caballeros, en su ficción los nobles se visten de pastores. Esta situación le permite analizar desde el prisma de distintos personajes, algo inusitado en un libro de caballerías, la importancia del vestido como marcador de clase concluyendo, como el autor se esmera en mostrar, que el elemento fundamental para poder pertenecer a jerarquías superiores no es la riqueza en el vestido sino la nobleza de sangre. El atuendo no puede seguir siendo ya símbolo de clase, ni tampoco las rentas, el número de servidores, etc. Todos esos elementos, relacionados directamente con el poder económico, pasan a un segundo plano y ahora surge otro valor que adquiere más importancia que el dinero, la sangre. Un nuevo valor que había que remarcar en un 
mundo donde la burguesía comenzaba a tener tantas o más riquezas que las familias aristocráticas y donde el linaje era el único elemento inalienable. Las dudas, debates y contradicciones presentes en esta obra son reflejo de la sociedad cambiante de la época donde los preceptos se cuestionan para determinar su validez y ofrecer otros modelos sociales acordes con la nueva realidad que surge. Esta obra refleja el momento coetáneo al autor donde unas nuevas estructuras, que están apareciendo, se establecerán con la misma fuerza que las anteriores. En los años venideros, el vestido dejará de abrumar por su lujo, al contrario, será sobrio y de elegancia austera pues la verdadera jerarquía está en la sangre.

\section{BIBLIOGRAFÍA}

Bernis, C., Indumentaria española en tiempos de Carlos V, Madrid, Instituto Diego Velázquez, del Consejo Superior de Investigaciones Científicas, 1962.

Del Río Barredo, M. J., Madrid, Urbs Regia. La capital ceremonial de la Monarquía Católica, Madrid, Marcial Pons, 2000.

EisenberG, D. y MARín PinA, Ma. C., Bibliografía de los libros de caballerías castellanos, Zaragoza, Prensas Universitarias de Zaragoza, 2000.

Guevara, A. de, Aviso de privados, viII, pp. 146-147. Disponible en: http:/ / www.filosofia. org/cla/gue/guepc.htm [consultado 03-03-2019].

Jones, A. R. y Stallybrass, P., Renaissance Clothing and the Materials of Memory, New York, Cambridge University Press, 2003.

Muguruza Roca, I., «El pastor en los libros de caballerías: El caso del Olivante de Laura, de Antonio de Torquemada», Cuadernos para la investigación de la literatura hispánica, 20 (1995), pp. 197-215.

Torquemada A. de, Olivante de Laura, I. Muguruza Roca (ed.), Madrid, Biblioteca Castro, 1997.

SEMPERE y GUARINOS, J., Historia del lujo y de las leyes suntuarias de España, vols. I-II, Gráficas Bachende, Madrid, 1788. 